\title{
Ernst Reuter-Vorlesung
}

im Wissenschaftskolleg zu Berlin

23. JUNI 1994 


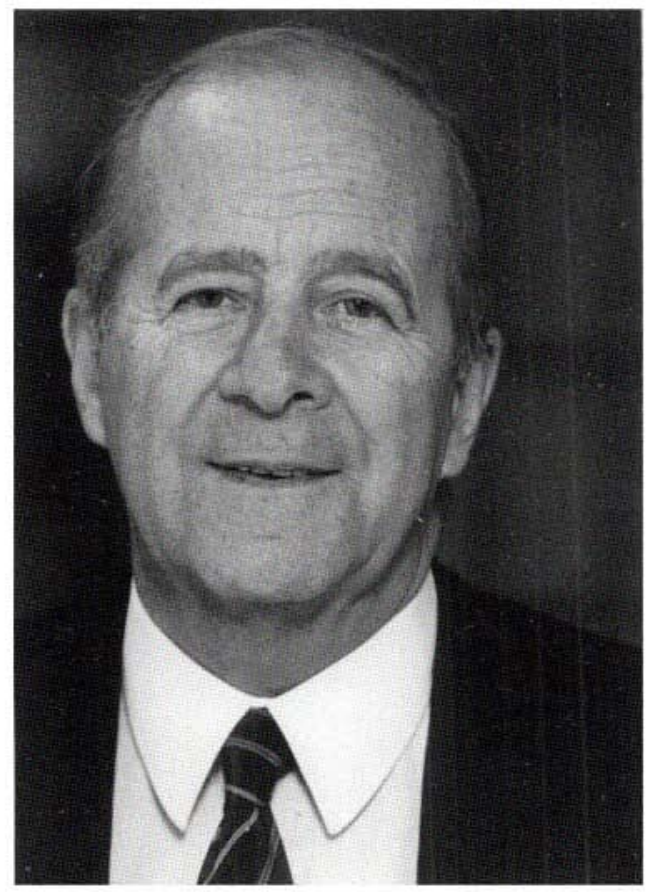




\section{JEAN FRANÇOIS-PONCET}

Globale Herausforderungen Europäische Antworten

Défis globaux Réponses européennes

Mit einer Vorrede von Wolf Lepenies

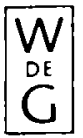

Walter de Gruyter · Berlin · New York 1995 
(2) Gedruckt auf säurefreiem Papier, das die US-ANSI-Norm über Haltbarkeit erfüllt.

\section{Die Dextsche Bibliotbek - CIP Einheitsaufnabme}

\section{François-Poncet, Jean:}

Globale Herausforderungen - europäische Antworten = Défis globaux - réponses européennes / Jean François-Poncet. Mit einer Vorr. von Wolf Lepenies. - Berlin ; New York : de Gruyter, 1995

(Ernst Reuter-Vorlesung im Wissenschaftskolleg zu Berlin ; 1994)

ISBN 3-11-014718-1

NE: GT

(C) Copyright 1995 by Walter de Gruyter \& Co., D-10785 Berlin Dieses Werk einschließlich aller seiner Teile ist urheberrechdich geschützt. Jede Verwertung außerhalb der engen Grenzen des Urheberrechtsgesetzes ist ohne Zustimmung des Verlages unzulässig und strafbar. Das gilt insbesondere für Vervielfältigungen, Übersetzungen, Mikroverfilmungen und die Einspeicherung und Verarbeitung in elektronischen Systemen.

Printed in Germany

Satz und Druck: Arthur Collignon GmbH, Berlin Buchbinderische Verarbeitung:

l.üderitz \& Bauer Buchgewerbe GmbH, Berlin 